\title{
MODERNIDADE E CRISE AMBIENTAL
}

\author{
Antônio Carlos dos Santos \\ Agripino Alexandre dos Santos Filho \\ Universidade Federal de Sergipe
}

\begin{abstract}
Resumo: 0 presente artigo analisa implicações entre a modernização das sociedades e a crise ambiental, com base na Teoria Social de Jürgen Habermas, que compreende o desenvolvimento das sociedades como processo de diferenciação entre o Mundo da Vida e Sistema, mediante a aprendizagem dos sujeitos, tanto na dimensão instrumental (trabalho), quanto na dimensão comunicativa (interação), em uma perspectiva alternativa em relação à proposta de Max Weber, que prioriza em sua análise a racionalidade instrumental. Inicialmente, são analisados os conceitos de sujeito e subjetividade (racionalidade), a fim de apresentar a proposta habermasiana de uma "racionalidade comunicativa". Na sequência, serão analisados os constructos teóricos "trabalho", "interação", "mundo da vida" e "sistema", centrais na teoria social habermasiana. Por fim, serão apresentadas as ideias de Habermas sobre o desenvolvimento das sociedades em sua dupla dimensão e suas consequências para compreensão da crise ambiental contemporânea.
\end{abstract}

Palavras-chave: Sociedade Moderna, Mundo da Vida, Sistema, Crise Ambiental.

Abstract: This paper examines implications of the modernization of societies and the environmental crisis, based on Jürgen Habermas Social Theory, which comprises the development of society as a process of differentiation between the World of Life and system, by learning the subjects, both in the instrumental dimension (work), and in the communicative dimension (interaction) in an alternative perspective on the proposal of Max Weber, in his analysis that prioritizes the instrumental rationality. Initially, we analyze the subject concepts and subjectivity (rationality) to present Habermas's proposal of a "communicative rationality". Following the theoretical constructs will be analyzed "work", "interaction", "life-world" and "system" central to Habermas's social theory. Finally, the ideas of Habermas on the development of societies in two dimensions and its implications for understanding contemporary environmental crisis will be presented.

Keywords: Modern Society, World of Life, System, Environmental Crisis.

A sociologia clássica se ocupou da análise do processo de modernização das sociedades, apresentando-o como um processo de racionalização, que desencantou o mundo, em razão da qual a empresa capitalista assumiu a centralidade do subsistema econômico e o Estado Nacional assumiu a centralidade do subsistema político, monopolizando o uso legítimo da violência, a produção do direito, a administração da justiça, a 
cobrança de tributos, a defesa do território contra ameaças internas e externas. Habermas aclara:

O conceito de modernização refere-se a um conjunto de processos cumulativos e de reforço mútuo: à formação de capital e mobilização de recursos; ao desenvolvimento das forças produtivas e ao aumento da produtividade do trabalho; ao estabelecimento do poder político centralizado e à formação de identidades nacionais; à expansão dos direitos de participação político, das formas urbanas de vida e da formação escolar formal; à secularização de valores e normas etc. (2002, p.5).

Em sua teoria da sociedade, Habermas propõe uma análise do desenvolvimento das sociedades políticas modernas, fundada em uma reformulação da ideia weberiana de racionalização, apresentando o desenvolvimento das sociedades como um processo de diferenciação dos subsistemas econômico e político, em duas dimensões: instrumental e comunicativa. O desenvolvimento das sociedades até o estágio da modernidade é visto por Habermas em uma perspectiva histórica, em busca de uma teoria social que seja útil, tendo como fio condutor a distinção entre os constructos teóricos "trabalho" e "interação", que resultará na diferenciação habermasiana entre racionalidade instrumental e racionalidade comunicativa, afirmando-se que o desenvolvimento das sociedades avança nessas duas dimensões. O desenvolvimento das sociedades emerge na obra de Habermas como um processo de aprendizagem social dialógico, balizado pelo principio de organização social de cada sociedade.

A partir das ideias de Habermas sobre o desenvolvimento social em sua dupla dimensão, pretende-se analisar a crise ambiental que afeta as sociedades modernas, tomando-se como marco inicial a compreensão habermasiana do conceito de razão instrumental em Weber.

\section{Modernidade e a razão instrumental}

Weber identificou o processo de modernização das sociedades com a crescente racionalização instrumental que se alastra por todos os setores sociais. Neste contexto, em Weber, o desenvolvimento das sociedades reflete o processo pelo qual a racionalidade instrumental se torna norma na modernidade, condicionando o agir dos indivíduos à sua lógica, que se identifica com a ideologia do modo de produção capitalista. Isto implica dizer que o processo de modernização das sociedades substituiu as formas tradicionais e carismáticas de dominação pela dominação racional-legal e, quanto mais as relações sociais se tornam complexas, mais aumenta a necessidade de racionalização, mediante a ampliação do aparelho burocrático do Estado e do seu ordenamento jurídico, garantido pelo monopólio do uso 
legítimo da violência física.

$\mathrm{Na}$ modernidade, a dominação não se exerce pela tradição ou pelo carisma do líder, mas em razão do lugar que a autoridade ocupa na hierarquia do aparelho burocrático do Estado, garantido pelo direito. Dessa forma, nas sociedades capitalistas, o Estado monopoliza o uso da violência para exercer duas funções: (a) função administrativa, pela qual o Estado organiza e administra a sociedade; (b) função de dominação política, pela qual o Estado garante a manutenção da relação de exploração, em que uma classe se apropria do excedente produzido por outra. Nas próprias palavras de Weber:

Em todos os tempos, os agrupamentos humanos mais diversos - a começar pela família - recorreram à violência física, tendo-a como instrumento normal do poder. Em nossa época, entretanto, devemos conceber o Estado contemporâneo como uma comunidade humana que, dentro dos limites de determinado território - a noção de território corresponde a um dos elementos essenciais do Estado - reivindica o monopólio do uso legitimo da violência (WEBER, 2007, p.56).

Assim, Weber definiu o Estado, não pelos seus fins, mas pelo meio pelo qual alcança seus fins: o monopólio do uso da violência legítima. Esse monopólio da coação física é a diferença específica entre o Estado e os demais agrupamentos humanos, que só podem exercer a violência dentro do território estatal nos limites autorizados pelo próprio Estado, que o utiliza como um instrumento de dominação.

Tal como todos os agrupamentos políticos que historicamente o precederam, o Estado consiste numa relação de dominação do homem sobre o homem, fundada no instrumento da violência legítima (isto é, da violência considerada como legítima). O Estado só pode existir, portanto, sob condição de que os homens dominados se submetam à autoridade dos dominadores (WEBER, 2007, p.57).

Habermas argumenta que Max Weber utilizou o conceito de racionalização para analisar as implicações do avanço da ciência e da técnica na formação das sociedades, a fim de explicar a passagem das sociedades tradicionais para as sociedades modernas.

O conceito de modernização refere-se a um conjunto de processos cumulativos e de reforço mútuo: à formação de capital e mobilização de recursos; ao desenvolvimento das forças produtivas e ao aumento da produtividade do trabalho; ao estabelecimento do poder político centralizado e à formação de identidades nacionais; à expansão dos direitos de participação político, das formas urbanas de vida e da formação escolar formal; à secularização de valores e normas etc. (HABERMAS, 2002, p.5).

Neste processo de modernização, as relações sociais sofrem o impacto dos subsistemas econômico e político-administrativo, que racionalizam o agir social, baseando-o em normas institucionalizadas, aceitas 
como obrigatórias pelos indivíduos (legitimadas) e garantidas pelo aparelho coercitivo do Estado, tornando-o um agir instrumental. A normatização estatal é internalizada pelos indivíduos, que concordam com as regras uniformes de comportamento estabelecidas pela dominação estatal, na medida em que estas permitem um relacionamento bilateral, onde o comportamento de um indivíduo, conforme a regra institucionalmente estabelecida, gera uma expectativa de que o outro também se comporte da maneira prescrita pelo ordenamento jurídico.

Para Habermas, Weber cuida essencialmente de uma racionalidade formal com base e uma relação entre meios e fins, que não remete a justificações posteriores.

Weber es un escéptico en cuestiones normativas: está convencido de que la decisión entre los distintos sistemas de valores (por más clarificados que estén analíticamente) no puede fundamentarse con razones, no puede ser motivada racionalmente; en puridad, no hay una racionalidad de los postulados valorativos o de las convicciones de valor últimas en lo que atañe a sus contenidos (HABERMAS, 2012, p.213).

Desse modo, para Habermas, a ideia weberiana de modernização das sociedades centra-se na institucionalização de um agir instrumental, voltado à obtenção de resultados pré-determinados, sem quaisquer avaliações morais quanto aos fins, que se estende a todas as áreas do sistema social, afetando as relações cotidianas dos seres humanos. Este agir estratégico se fundamenta em uma racionalidade técnica e científica, que planeja a utilização dos meios para obtenção de determinados fins, erguendo-se contra a tradição, seus mitos e crenças, em prestígio de um saber racional, que possibilita o domínio da Natureza e dos seres humanos uns pelos outros.

A crítica de Habermas se dirige a essa racionalidade unidimensional de Weber, propondo um novo enfoque bidimensional da racionalidade: instrumental e comunicativa. O contraponto habermasiano ao pensamento de Weber se lastreia na diferenciação dos constructos teóricos "trabalho" e "interação".

\section{Trabalho e interação}

Em Habermas, o trabalho é compreendido como a ação instrumental orientada por regras técnicas, descritivas de fenômenos naturais ou sociais, que têm por objetivo a dominação da Natureza e o aumento da produção, com vistas à obtenção de resultados predeterminados e sujeita ao critério de veracidade. A ação instrumental só tem algum valor na medida em que efetivamente permite a obtenção do resultado pretendido, do contrário, é inútil. As regras técnicas da dimensão "trabalho" descrevem as relações de 
causalidade do mundo natural, no plano do "ser", ou seja, "se for A é B", e, por isso não podem contrariar os fatos sob pena de se tornarem inúteis e terem que ser substituídas.

Em sentido diverso, a ação comunicativa é "uma interação simbolicamente mediada", que se estabelece mediante normas de conduta reciprocamente reconhecidas como válidas pelos indivíduos, instituindo expectativas de comportamento entre os interlocutores, reforçadas por sanções. As regras sociais do agir comunicativo se dirigem à conduta do ser humano em interação, com vistas a determinar como os seres humanos devem se comportar intersubjetivamente, no plano do "dever-ser", ou seja, "se for A deve ser B", onde o conseqüente "B" é imposto convencionalmente pela vontade humana em interferência intersubjetiva.

Habermas aclara:

A ação instrumental orienta-se por regras técnicas que se apoiam no saber empírico. Estas regras implicam em cada caso prognoses sobre eventos observáveis, físicos ou sociais; tais prognoses podem revelar-se verdadeiras ou falsas. $\mathrm{O}$ comportamento da escolha racional orienta-se por estratégias que se baseiam num saber analítico. Por outro lado, entendo por ação comunicativa uma interação simbolicamente mediada. Ela orienta-se segundo normas de vigência obrigatória que definem as expectativas recíprocas de comportamento e que têm de ser entendidas e reconhecidas, pelo menos, por dois sujeitos agentes. As normas sociais são reforçadas por sanções (2001, p.57).

Portanto, as regras técnicas e as regras sociais também se distinguem quanto às consequências do seu descumprimento, uma vez que as regras sociais são obrigatórias, ou seja, têm sua imposição garantida pelo poder institucionalizado do grupo social, independentemente e mesmo contra a vontade dos destinatários, inclusive mediante o uso legítimo da violência. As regras sociais não perdem a validade apenas em razão dos fatos não ocorrerem como elas prescrevem, pois o grupo social possui mecanismos institucionais para impor a decisão convencionada intersubjetivamente e reconhecida, mediante a aplicação de uma sanção. Enquanto as regras técnicas do agir instrumental se submetem a uma causalidade natural, as regras éticas do agir comunicativo se submetem a uma normatividade.

Habermas avança na análise dos constructos teóricos "trabalho" e "interação", mediante a contraposição do pensamento do jovem Hegel às ideias kantianas. Para Kant, a razão humana só podia conhecer o fenômeno, jamais o númeno (coisa-em-si), por isso constrói um conceito de razão limitada à mente humana, que se dirige à Natureza para conhecê-la. Com efeito, a ideia kantiana de "Eu" expressa um conceito de sujeito transcendental, a-histórico, abstrato, cuja razão monológica e auto-referida organiza o caos da natureza externa, a fim de conhecê-la (razão teórica) e 
determinar regras de conduta para o agir humano (razão prática), propondo máximas universais.

Habermas esclarece que o jovem Hegel, nas lições de Iena (18011807), apresentou contra Kant, a ideia de um processo de formação heterogênea do sujeito (consciência), por três meios originários e independentes, mas relacionados: (i) a família, meio no qual o sujeito adquire a consciência de sua própria existência, mediante uma dialética da interação, de viés intersubjetivo, que proporciona o reconhecimento recíproco, instituindo uma consciência reconhecida; (ii) a linguagem, meio constituído por símbolos que o sujeito utiliza para nomear as coisas que o cercam e assim apartar-se delas, ou seja, pela e na linguagem o ser humano transcende seus meros instintos animais e "se separam, para a consciência, o ser da consciência e o ser da natureza. O espírito, por assim dizer, desperta do seu sonho quando o reino das imagens se traduz para o reino dos nomes." (HABERMAS, 2001, p. 24). $\mathrm{Na}$ linguagem se institui uma dialética da representação, que institui uma consciência nomeante; (iii) o trabalho, meio constituído pelos instrumentos que o sujeito utiliza para subjugar os processos naturais e assim satisfazer suas necessidades, conduzindo a uma consciência astuta ou instrumental. Enquanto o símbolo descreve a Natureza, o instrumento permite sujeitá-la. Para Habermas, encontra-se no jovem Hegel uma ideia de formação dialógica do espírito humano, que se constitui em sua relação com os demais.

A dialética da autoconsciência de Hegel ultrapassa a relação da reflexão solitária,
em prol da relação complementar dos indivíduos. A experiência da
autoconsciência já não figura como originária. Para Hegel, resulta antes da
experiência da interação, em que Eu aprendo a ver-me com os olhos do outro
sujeito. A consciência de mim mesmo deriva de um entrelaçamento das
perspectivas. Só com base no reconhecimento recíproco se forma a
autoconsciência, que se deve fixar no reflexo de mim mesmo na consciência de
um outro sujeito (HABERMAS, 2001, p.14-15).

Para Habermas, o pensamento do jovem Hegel não dilui a interação no trabalho, mas permite compreender a relação entre ambos. A relação entre "trabalho" e "interação" ocorre no trabalho social, que estabelece a divisão de trabalho e o intercâmbio dos produtos, cujos comportamentos são institucionalizados e garantidos pelo direito na instituição do contrato, que assegura a reciprocidade dos comportamentos esperados.

Foi precisamente essa relação entre o trabalho e a interação que Habermas entende ter sido abandonada por Hegel e, posteriormente, retomada por Marx, que "sem ter conhecimento dos manuscritos de Iena, redescobre na dialética de forças produtivas e relações de produção essa conexão do trabalho e interação" (HABERMAS, 2001, p.41). Entretanto, Habermas aclara e critica o desenvolvimento do pensamento de Karl Marx, que termina por reduzir o 
agir comunicativo ao agir instrumental, absorvendo os aspectos práticos na dimensão da técnica, permitindo uma interpretação mecanicista pela qual existiria uma relação necessária entre o "trabalho" e a "interação". Habermas afirma:

A emancipação relativamente à fome e à miséria não converge necessariamente com a libertação a respeito da servidão e da humilhação, pois não existe uma conexão evolutiva automática entre interação e trabalho. Apesar de tudo, existe uma relação entre os dois momentos (2001, p.42).

Habermas enfatiza a irredutibilidade entre o "trabalho" e a "interação" para reconstruir, a partir dessa irredutibilidade, o conceito de racionalidade, analisando a diferenciação e a relação entre o "trabalho" e a "interação" em duas vertentes do seu pensamento: (a) a teoria da ação comunicativa, em que trata da ação orientada ao consenso, como fundamento da legitimação democrática; e (b) a teoria crítica da sociedade, em que discute o desenvolvimento das sociedades tardocapitalistas. Ambas as vertentes estão interligadas, mas para os fins deste artigo, cumpre radicalizar a análise da segunda, a partir das categorias habermasianas fundamentais de Sistema e Mundo da Vida.

\section{Sistema e mundo da vida}

Habermas parte da ideia de que o "trabalho" e a "interação" são conceitos diferentes e irredutíveis um ao outro, mas interligados, de modo que o desenvolvimento das sociedades como processo de racionalização deve avançar em ambas as categorias, pois a emancipação material pela técnica não conduz mecanicamente à emancipação do espírito. A partir dessa diferenciação entre o "trabalho" e a "interação", Habermas analisa a sociedade sob cada um desses prismas, de modo que na perspectiva da interação, a sociedade é vista como (a) um Mundo da Vida, no qual se descortinam as relações comunicacionais entre seus membros, enquanto na perspectiva do trabalho a sociedade é vista como (b) um sistema de condução de ações. Trata-se de conceito dual de sociedade, que a um só tempo pode ser compreendida como Mundo da Vida e Sistema.

Deveras, os seres humanos nascem imersos em uma cultura, que se constitui de valores, crenças e conceitos compartilhados linguisticamente, por meio de símbolos, determinantes da pré-compreensão do mundo. O Mundo da Vida é precisamente esse horizonte de pré-compreensão intersubjetivamente compartilhado, que estabelece o quadro institucional normativo para as relações intersubjetivas entre seres humanos capazes de agir e falar, constituindo a condição de possibilidade do entendimento mútuo, promovendo a integração social. 
Em contraposição ao Mundo da Vida se ergue o Sistema, que é um mecanismo de condução das ações humanas, com vistas ao domínio da complexidade do ambiente externo para manutenção dos limites do sistema social. Sob a perspectiva sistêmica, a sociedade é um sistema de sistemas, ou seja, um sistema global que possui sistemas parciais ou subsistemas, que promovem a integração sistêmica. A sociedade necessita de ambas as formas de integração, social e sistêmica, uma vez que atua na apropriação e controle da natureza interna (relações entre os seres humanos em sociedade) e da natureza externa (relação sociedade-natureza).

A apropriação da natureza interna ocorre mediante os processos de socialização, que moldam o caráter do ser humano ao convivo social, desde o momento em que ele nasce e por toda sua vida, tornando-o membro de um sistema social, com capacidade de falar e agir. A apropriação da natureza externa ocorre mediante os processos de produção, que consistem em ações instrumentais, baseadas em regras técnicas.

Os processos de socialização promovem a adaptação social da natureza interna por meio de normas que admitem pretensões de validade, ou seja, admitem normas que disciplinam a conduta humana e necessitam de justificação. As normas que organizam o comportamento humano em sociedade são produzidas linguisticamente, o que pressupõe uma estrutura intersubjetiva que permita a comunicação. A normatização social supera o subjetivismo do indivíduo pela generalização de valores materializada em normas válidas, dotadas de legitimidade, que asseguram um significado comunitário, capaz de instituir um Mundo da Vida compartilhado intersubjetivamente. Essa cosmovisão compartilhada assegura a identidade da sociedade e permite a integração social. Já os processos de produção promovem a adaptação social da natureza externa pelo trabalho (ação instrumental), de forma organizada e com base em regras técnicas que admitem pretensões de verdade, ou seja, o controle da natureza externa ocorre mediante regras empíricas que se pretendem verdadeiras e que são redimíveis discursivamente, podendo ser reconstruídas racionalmente. $\mathrm{Na}$ medida em que uma sociedade se desenvolve, aumenta o seu domínio sobre as naturezas interna e externa, mediante a utilização de instrumentos normativos e técnicos, ampliando sua capacidade de condução para responder às variações do ambiente com alterações de seus padrões de normalidade, adaptando-se aos novos arranjos sociais.

Habermas enfatiza que o desenvolvimento dos processos de produção aumenta sempre a capacidade de condução do sistema social, ampliando o controle sobre a natureza externa, mas o desenvolvimento dos processos de socialização não acarreta necessariamente o mesmo resultado sobre a natureza interna. Ou seja, não há uma correlação necessária entre o 
desenvolvimento das regras técnicas, que orientam as ações instrumentais de produção e o desenvolvimento das estruturas normativas da sociedade, que promovem a integração social, na medida em que o desenvolvimento dos processos de produção aumenta sempre a capacidade de condução do sistema, mas o desenvolvimento dos processos de socialização não se traduz necessariamente em uma ampliação do domínio sobre a natureza interna.

Mais ainda, o desenvolvimento da integração sistêmica, com o aperfeiçoamento do domínio instrumental sobre a Natureza, pode conduzir ao questionamento das estruturas normativas da sociedade, tendo em vista o descompasso entre as imagens de mundo legitimantes e o saber técnico produzido. Os processos de produção podem ser compreendidos como uma redução da complexidade do conjunto, pois o aperfeiçoamento da ação instrumental de produção acarreta o aumento do controle sobre a natureza externa, ampliando a capacidade de condução do sistema social, mas os processos de socialização não seguem essa mesma lógica, porque a natureza humana jamais se dilui por completo após a socialização. Logo, a adaptação da natureza interna não pode ser tratada como uma redução da complexidade do conjunto, na medida em que a socialização aumenta paradoxalmente a capacidade do indivíduo em resistir ao poder do sistema, falando e agindo no espaço intersubjetivamente construído. Enfim, para Habermas, as sociedades se desenvolvem e se classificam a partir da predominância da racionalidade instrumental ou da racionalidade comunicativa, com base em seu princípio de organização, nos limites do qual ocorre o processo de aprendizagem social.

\section{O desenvolvimento da sociedade como processo de diferenciação entre o mundo da vida e o sistema}

Em sua teoria social, Habermas parte da divisão social do trabalho proposta por Durkheim para analisar o desenvolvimento das sociedades, tendo em vista a passagem de estruturas sociais mais simples para estruturas sociais mais complexas. Durkheim expôs que a constituição e permanência das formações sociais demandam um consenso entre os indivíduos sobre as normas de comportamento, capaz de manter a coesão social, nomeado por ele de solidariedade social. As formações sociais possuem uma consciência coletiva, que é mais que a simples soma das consciências individuais, constituindo-se das crenças e dos valores morais que são transmitidos entre as gerações, formando a identidade do grupo social, influenciando nas decisões e comportamentos individuais e produzindo nos indivíduos de um mesmo grupo o sentimento de pertencimento. Nas sociedades primitivas, essa consciência coletiva é bastante forte, gerando uma identificação entre os indivíduos com a sociedade a qual pertencem, que se vêem como semelhantes, 
fazendo prevalecer a consciência coletiva sobre as consciências individuais, mediante um consenso fundado na tradição, nomeado por Durkheim de solidariedade mecânica. Para Durkheim, as sociedades modernas surgem com diferenciação social do trabalho, pela qual os indivíduos passam a exercer funções distintas e interligadas, de modo semelhante às funções exercidas pelos diferentes órgãos de um ser vivo, estabelecendo uma espécie de solidariedade nomeada de solidariedade orgânica, na qual prepondera a consciência individual. $\mathrm{O}$ aumento de complexidade das relações sociais força um maior intercâmbio entre os indivíduos, que se vêem compelidos a interligarem suas atividades, a fim de possibilitar a sobrevivência, operando a passagem da solidariedade mecânica para a solidariedade orgânica, que se torna preponderante. Quanto maior a divisão social do trabalho, mais os indivíduos se tornam interdependentes, enfraquecendo a consciência coletiva e aumentando a solidariedade orgânica, motivo pelo qual Durkheim afirma ser "uma lei da história a de que a solidariedade mecânica, que, a princípio, é única ou quase, perde terreno progressivamente e que a solidariedade orgânica se torna pouco a pouco preponderante" (2010, p.157).

Nesse contexto, Habermas afirma que a tese de Durkheim conduz à conclusão de que a solidariedade nas sociedades primitivas se fundamenta em uma consciência coletiva, enquanto a solidariedade nas sociedades modernas se fundamenta na divisão social do trabalho, logo, o desenvolvimento das sociedades ocorre em razão da modificação da base de integração social. A partir desta constatação, Habermas propõe que se entenda a sociedade simultaneamente como "Mundo da Vida" e como "Sistema", como já tratamos no item anterior, fazendo desta concepção dual de sociedade o caminho para a compreensão do seu desenvolvimento.

Habermas utiliza as categorias de "Mundo da Vida" e "Sistema" para analisar as formações sociais, com base na predominância do agir instrumental ou do agir comunicativo, permitindo estabelecer um padrão de comparação capaz de delinear o desenvolvimento das sociedades, a partir do seu princípio de organização, diferenciando quatro formações sociais, (a) primitivas ou "anteriores às altas culturas"; (b) tradicionais; (c) capitalistas (do capitalismo liberal, do capitalismo tardio ou do pós-capitalismo); (d) pós-modernas, detendo-se na análise das três primeiras, a fim de explicar o desenvolvimento das sociedades, mediante o processo de aprendizagem limitado pelo princípio de organização social.

Acerca do processo de aprendizagem em Habermas, Oliveira pontua:

Para haver tal processo comunicativo, pressupõe-se um processo de aprendizagem entre os sujeitos, um descentramento dos mesmos que se referencia tanto no mundo circundante através das experiências vividas, como 
na experiência consigo mesmo. "Em um processo de formação, nós só aprendemos sobre o mundo aquilo que experimentamos ao mesmo tempo em nós mesmos como sujeitos que aprendem [...]" (HABERMAS, 2009, p. 283). Esta lógica de aprendizagem, que Habermas também estende às sociedades, é fundamental para a proposta do autor de sair da subjetividade e entrar no processo intersubjetivo (OLIVEIRA, 2014, p.22).

Nesse sentido, nas sociedades primitivas, o princípio de organização é o sistema de parentesco, que não permite diferenciação entre integração sistêmica e integração social, e as crises ocorrem em razão de fatores externos; nas sociedades tradicionais, o princípio de organização é o sistema de dominação política e divisão de classes, que diferencia as funções de integração sistêmica e integração social, e as crises ocorrem em razão de fatores internos; nas sociedades capitalistas, o princípio de organização é a relação entre o capital e o trabalho assalariado, garantida pelo direito racional burguês, que atribui ao mercado a função de promover a integração sistêmica e a integração social, de modo que todo problema de condução econômica se torna uma crise sistêmica.

\section{Comentando este aspecto, Kelm et al aclaram:}

Dessa forma, Habermas considera que ocorre uma evolução das estruturas de mundos-da-vida históricos, de modo que a sociedade vai incorporando elementos morais que avançam pelos estágios pré-convencional, convencional e, hipoteticamente, pós-convencional propostos por Kohlberg (1958). Nessa evolução, o aumento da complexidade sistêmica somente pode ocorrer pela adoção de um novo mecanismo sistêmico que deve ser institucionalizado na forma de estruturas morais e legais, viabilizando, na sequência, as transformações materiais intencionais promovidas pelos diversos atores sociais. É a partir desse novo estágio do subconsciente coletivo que se estabelecerão as novas relações e as novas conformações visíveis das estruturas normativas da sociedade (2014, p.403s).

Portanto, a contraposição entre o "Mundo da Vida" e o "Sistema" é fundamental para compreensão da teoria social de Habermas, cujo diagnóstico infere que as patologias da modernidade decorrem precisamente da colonização do "Mundo da Vida" pelo "Sistema", ou seja, os subsistemas Dinheiro e Poder se autonomizaram e estenderam sua racionalidade instrumental aos contextos de interação comunicativa do "Mundo da Vida", instrumentalizando as relações sociais e bloqueando a comunicação livre, a fim de manipular as opiniões e as pessoas. Habermas defende que as estruturas normativas são dinâmicas o suficiente para possibilitar o julgamento crítico acerca princípio de organização social, seus limites e insuficiências, pois o processo de aprendizagem social não se detém, mesmo quando há eventuais retrocessos.

Este modelo habermasiano de compreensão do desenvolvimento das 
sociedades pode ser utilizado para analisar a crise ambiental moderna, que possui uma dupla dimensão e um caráter eminentemente paradigmático.

\section{A crise ambiental moderna}

O projeto da modernidade, iniciado no século XVI, incluía em sua agenda a emancipação do ser humano pela extensão do seu domínio sobre a natureza, tendo Francis Bacon como seu precursor, cuja ideia central era que o "saber é poder". Portanto, era necessário ampliar o conhecimento sobre a natureza, a fim de estender o poder do ser humano sobre os fenômenos naturais, mediante uma linguagem e um método libertos da tradição teológica medieval, que entendia a natureza como uma obra de Deus, merecedora de contemplação, não de estudo.

A relação entre as sociedades modernas e a Natureza se constrói em torno da ideia de exterioridade do ser humano em relação à Natureza, esta compreendida como matéria inerte, sem propósito ou valor intrínseco, sujeita ao conhecimento e ao controle ilimitado pelo ser humano como único ser moral, tendo como meta a emancipação do ser humano do reino da necessidade, estabelecendo as condições para o progresso material e moral de toda a humanidade. O método da ciência moderna, de caráter experimental e racional-matemático, possibilitou o conhecimento e domínio dos processos naturais, proporcionando o desenvolvimento da técnica e a promoção do bemestar em diversas áreas da vida humana.

Todavia, a pretendida emancipação do ser humano não ocorreu. Ao contrário, precisamente agora, quando o domínio do ser humano sobre a Natureza parece ter alcançado sua plenitude, vê-se o retorno da intolerância e da irracionalidade, bem como as consequências dos problemas ecológicos decorrentes das intervenções antrópicas se agravarem, de modo que as promessas da modernidade ficaram sem cumprimento, enquanto as sociedades modernas marcham para o colapso ecológico, com grave ameaça à continuidade da existência humana digna.

Destarte, a chamada crise ambiental moderna emerge em meio ao processo de colonização do "Mundo da Vida", rompendo a dinâmica entre a domesticação das naturezas interna e externa, em prestígio da hipertrofia do agir instrumental. Importa destacar que o agir instrumental é imprescindível para o desenvolvimento das sociedades, pois os seres humanos sempre extraíram sua sobrevivência intervindo na Natureza desde sempre, inicialmente mediante tecnologias primitivas para atender às necessidades de grupos sociais pequenos e de características nômades, razão pela qual suas atividades produziam um baixo impacto nas relações ecossistêmicas. Com a invenção da 
agricultura, os seres humanos passaram a se fixar em determinado local, cultivando grãos e domesticando animais, perdendo assim a característica nômade e, a partir desse marco, seguiu-se a complexificação das sociedades, o aumento demográfico e o advento de novas tecnologias foram ampliando o potencial interventivo do ser humano na natureza.

Deste modo, é forçoso concluir que sempre existiram problemas decorrentes da intervenção humana na natureza, variando apenas o grau, mas sempre com reflexos importantes para as sociedades humanas, pois a poluição de um pequeno riacho poderia ser tão grave para os primitivos hominídeos quanto um grande derramamento de óleo no oceano é para as sociedades contemporâneas. $\mathrm{O}$ signo distintivo da crise ambiental moderna consiste no seu âmbito global e a contração do tempo, de modo que as consequências das intervenções humanas na Natureza se fazem sentir em intervalos cada vez mais curtos e em espaços territoriais cada vez mais amplos. A quebra do limite espaço-temporal permite afastar a poluição de um pequeno riacho feita pelo ser humano primitivo de um desastre ecológico promovido pelo ser humano moderno.

Liberto de quaisquer limites físicos, tecnológicos e morais, o agir instrumental moderno reconhece apenas uma relação entre meios e fins, que desconsidera a manutenção da base material que sustenta a vida e, por isso mesmo, assume uma feição suicida, ocultada pela ideologia do progresso, que potencializa o fenômeno chamado por Habermas de "privatismo cívico": a ação social passa a se orientar pela obtenção de benefícios concedidos pelo sistema. A esse "privatismo cívico" se soma e um "privatismo familiar e profissional": a ação individual se orienta para o consumo de mercadorias supérfluas e para o sucesso na carreira profissional. Através desses dois fenômenos, o sistema legitima as decisões em relação às intervenções na Natureza e a divisão entre seus benefícios e riscos, sem a participação efetiva dos cidadãos, que são orientados para obtenção de benefícios e satisfação de interesses individuais. 
Desse modo, a partir de Habermas, é possível inferir que as sociedades modernas desenvolveram uma estrutura reativa à crise ecológica, que atua para ocultá-la ou ao mesmo suavizá-la, administrando-a politicamente, inclusive mediante a distribuição de recompensas que melhoram as condições materiais e o bem-estar de parcela, com vistas a tolher indiretamente sua liberdade e a autodeterminação, em face do temor em perder as concessões do sistema, identificadas como conquistas sociais. Esse cenário gera um acúmulo de problemas ecológicos que se retroalimentam e seguem uma espiral ascendente, que ameaça o quadro civilizatório moderno de colapso e dissolução.

\section{Considerações finais}

Jürgen Habermas propôs um modelo de desenvolvimento das sociedades como consequência da própria racionalidade do ser humano, que o impulsiona a aprender, aumentando o controle sobre a natureza externa e a integração da natureza interna, mediante pretensões de validade redimíveis discursivamente, de modo que o nível de capacidade de aprendizagem em uma sociedade revela o seu grau de racionalidade ou irracionalidade e segue um padrão.

A proposta habermasiana implica em uma ampliação do conceito de racionalidade para criticar a razão instrumental, apresentando o conceito de razão comunicativa, fundada no relacionamento intersubjetivo, livre e reflexivo, mediante o uso da linguagem, pela qual os interlocutores reivindicam, uns dos outros, pretensões de validade para seus enunciados e ações. Os discursos dos sujeitos são praticados mediante procedimento argumentativo que deve permitir um consenso racional e livre entre todos os concernidos possíveis. Ainda que não ocorra o acordo, o importante para Habermas é que os procedimentos de argumentação possibilitem efetivamente a discussão livre de coações, capaz de promover um consenso legítimo.

Habermas se opõe à ideia weberiana de desenvolvimento unidimensional das sociedades, fundado apenas na razão instrumental, propondo um novo conceito bidimensional de racionalização, que assegure a socialização intersubjetiva, mediante a ideia de uma racionalidade comunicativa, que descolonize o Mundo da Vida. Em Habermas, o desenvolvimento das sociedades depende das modificações nos processos de produção e de socialização, que seguem padrões possíveis de serem reconstruídos racional e historicamente, acompanhando o processo de desenvolvimento das sociedades, segundo sua capacidade de aprendizagem, determinada pelo seu princípio de organização. Nesse diapasão, o processo de modernização não se resumiu à hipertrofia da razão instrumental, mas também 
implicou em um aumento da necessidade de interação social para legitimação democrática do poder, ou seja, as sociedades modernas avançadas têm que enfrentar os desafios impostos pela democracia de massa, o que mantém vivo o potencial emancipador da razão comunicativa.

A crise ambiental moderna emerge no contexto da hipertrofia do agir instrumental, agravando-se pela instituição de uma estrutura reativa, que a oculta ou suaviza, protelando-a para mante a divisão assimétrica entre os benefícios e riscos decorrentes do agir instrumental, em prestígio de parcela da sociedade. A análise habermasiana do desenvolvimento das sociedades permite identificar as patologias da modernidade, retirando esse véu ideológico, que oculta ou suaviza a crise ambiental, permitindo uma reflexão acerca de suas causas para uma tomada consciente de decisão.

\section{Referências}

BANNWART JÚNIOR, C. J. "Perspectiva Evolucionária na Teoria Social Crítica de Habermas”. In: Trans/Form/Ação, Marília, v.36, p.67-86, 2013. Edição Especial.

DURKHEIM, É. Da divisão social do trabalho. Tradução Eduardo Brandão. $4^{\mathrm{a}}$ ed. São Paulo: Martins Fontes, 2010.

HABERMAS, J. Problemas de legitimación en el capitalismo tardío. Tradução José Luis Etcheverry. Madri: Ediciones Cátedra, 1999.

70, 2001.

. Técnica e ciência como ideologia. Tradução Artur Morão. Lisboa: Edições

- O discurso filosófico da modernidade. Tradução Luiz Sérgio Repa e Rodnei Nascimento. $1^{\mathrm{a}}$ ed., $2^{\mathrm{a}}$ tir. São Paulo: Martins Fontes, 2002.

. Teoria de la acción comunicativa: Tomo I. Racionalidad de la acción y racionalización social. Tomo II. Crítica de la razón funcionalista. Tradução Manuel Jiménez Redondo. Madri: Trotta, 2010.

KELM, M. L. et al. "Institucionalização das iniciativas socioambientais das organizações: interfaces entre a teoria do desenvolvimento social de Habermas e o isomorfismo da teoria institucional". In: Cad. EBAPE.BR, Rio de Janeiro, v.12, n. especial, Aug./2014.

OLIVEIRA, A. "Poder e verdade em Foucault e em Habermas". In: Acta Scientiarum. Human and Social Sciences, Maringá, v.36, n.1, p.19-25, July-Dec., 2014.

WEBER, M. Ciência e Política: duas vocações. Tradução Leonidas Hegenberg e 
Octany Silveira da Mota. São Paulo: Cultrix, 2007.

E-mail: acsantos12@uol.com.br

Recebido em: 02/2017

Aprovado em: 09/2017 